\title{
PENGARUH RASIO PROFITABILITAS DAN SOLVABILITAS TERHADAP PER PADA PERUSAHAAN TAMBANG BEI 2010-2019
}

\author{
${ }^{1}$ Nur Salma, ${ }^{2}$ Eko Wulan Pratiwi \\ Fakultas Bisnis, Universitas Mitra Indonesia \\ salma@umitra.ac.id, ekowulanpratiti@gmail.com
}

\begin{abstract}
Abstrak
Pada umumnya perusahaan harus menjaga dan meningkatkan ROA, DER, dan NPM perusahaan agar dapat bersaing dengan perusahaan lainnya. Apabila ROA, DER, dan NPM perusahaan tidak baik maka akan berdampak terhadap PER perusahaan. Oleh sebab itu, dilakukan penelitian ini untuk mengetahui tingkat kesehatan perusahaan tersebut. Pada penelitian ini peneliti menggunakan perusahaan sub sektor tambang batubara yang terdaftar di BEI dengan mengunakan data sekunder yang didapatkan melalui website resmi BEI dan rasio yang digunakan adalah rasio ROA, DER, NPM, dan PER. Desain penelitian yang digunakan pada penelitian ini adalah desain penelitian kuantitatif, pengambilan sampel pada penelitian ini menggunakan teknik purposive samplingdan sampel yang digunakan merupakan laporan keuangan tahunan perusahaan sub sektor batubara tahun 2010-2019. Berdasarkan hasil penelitian yang telah dilakukan penelitian secara keseluruhan bahwa variabel ROA, DER, dan NPM berpengaruh secara simultan terhadap variabel PER. Sedangkan secara parsial ROA berpengaruh dan signfikan terhadap PER namun secara parsial DER dan NPM tidak berpengaruh dan tidak sifnifikan terhadap PER.
\end{abstract}

Kata kunci : ROA, DER, NPM, dan PER

\begin{abstract}
Generally companies should maintain and improve ROA, DER, and NPM companies in order to compete with other companies. If ROA, DER, and NPM companies are not good then it will have an impact on PER company. Therefore, this research is done to know the level of health of the company. In this research, researchers use the IDX-registered coal mining sub-sector company by using secondary data obtained through the IDX official website and the ratios used are ROA, DER, NPM, and PER ratios. The research design used in this research is quantitative research design, sampling in this research using purposive sampling techniques and samples used is the annual financial report of coal sub-sector company in 2010-2019. Based on the research results that have been done in the overall research that the ROA, DER, and NPM variables are influential simultaneously on the PER variable. While in partial ROA is influential and insignificant to the PER but partially DER and NPM has no effect and is not an impact on the PER.
\end{abstract}

Keywords: ROA, DER, NPM, and PER 


\section{PENDAHULUAN}

Kegiatan industry telah semakin pesat sehingga diharuskan meningkatkan kinerja perusahaan agar lebih baik dimana persaingan pada pasar domestic dan pasar internasional menuntut perusahaan untuk selalu meningkatkan kualitas agar dapat mempertahankan dalam memperoleh laba dengan cara selalu memperhatikan kegiatan operasional dan financial perusahaan. Saat ini perusahaan industri telah mendominasi perusahaan-perusahaan yang terdaftar pada BEI salah satu perusahaannya yaitu perusahaan industri pertambangan dan Indonesia termasuk kedalam produsen dan eksportir batubara terbesar didunia. Berdasarkan berita yang telah disampaikan oleh Hidayat Setiaji selaku reporter CNBN Indonesia pada tanggal 05 April 2020 bahwa harga batubara anjlok sepanjang pekan ini. Bahkan harga batubara berada dititik terendah dalam nyaris empat tahun terakhir. Sepanjang minggu ini, harga si batu hitam ambrol mencapai 12,77\%. Pada akhir pekan, harga komoditas ini menyentuh titik terendah sejak Juli 2016. Pendapat Diana (2018:51) suatu kegiatan penjabaran angka yang telah ada dilaporan keuangan agar diketahui keberadaan keuangan pada perusahaan dan dapat memberikan penilaian terhadap kinerja manajemen perusahaan dalam waktu tertentu yang disebut analisis rasio keuangan. Rasio yang digunakan yaitu Rasio Profitabilitas dan Rasio Solvabilitas. Profitabilitas merupakan rasio yang memampu melihat perkembangan perusahaan pada saat mendapatkan keuntungan dan yang memiliki hubungan dengan nilai penjualan/pendapatan, asset dan equity. Rasio profitabilitas yang digunakan adalah NPM dan ROA selanjutnya, Rasio solvabilitas adalah kegiatan yang mampu menilai perkembangan perusahaan dalam memenuhi kewajiban financial baik dalam jangkapendek serta jangka panjang. Rasio solvabilitas yang digunakan yakni DER. Pendapat Budiman (2018:47) rasio yang bisa diperkirakan menggunakan cara dengan membandingkan harga saham pada pasar bursa dengan laba bersih per saham atau biasa disebut dengan Price Earing Ratio. Menurut Paramita dan Oktavia (2015) penelitian ini memiliki tujuan dengan menganalisis dan mendapatkan bukti emperis pengaruh ROA, NPM, dan DER terhadap harga saham.saham pada perusahaan manufaktur yang terdaftar di BEI periode 2011-2013. Menurut Manoppo, Tewal, dkk (2017) penelitian ini bertujuan untuk menganalisi pengaruh Debt to Equity (DER), Return on Asset (ROA) dan Net Profit Margin (NPM) terhadap harga saham secara simultan dan parsial. Objek pada penelitian ini yaitu perusahaan Food and Bevarages yang terdaftar di BEI. Menurut Hutapea, Saerang, dkk (2017) penelitian ini memiliki tujuan menganalisis pengaruh ROA, NPM, DER terhadap Harga Saham industri Otomotif dan Komponen di BEI tahun 2012-2016. Pertambangan merupakan kegiatan dengan sebagaian atau seluruh langkah yang meliputi penelitian, pengelolahan dan pengusahaan batubara yang meliputi penyelidikan umum, kontruksi, pemurnian, pengangkutan, penjualan dan kegiatan pertambangan. Terdapat beberapa perusahaan dengan sektor yang terdaftar pada BEI dan memiliki tingkat fluktuasi yang selalu berubah yaitu Perusahaan Sub Sektor tambang Batubara, hal ini disebabkan oleh tambang batubara yang merupakan salah satu penggerak perekonomian di Indonesia. Terdapat 22 perusahaan sub sektor tambang batubara yang terdaftar pada BEI dan telah go public dan terdapat 3 perusahaan berdasarkan kelengkapan data laporan keuangan perusahaan pada tahun 2010-2019. Berdasarkan identifikasi diatas sehingga peneliti tertarik melakukan penelitian dan menganalisis permasalahan atas ROA, DER, dan NPM terhadap perusahaan sub sektor tambang batubara yang terdaftar di BEI dengan judul "Pengaruh ROA, DER, NPM Terhadap PER Pada Perusahaan Sub Sektor Tambang Batubara Yang Terdaftar Di BEI Tahun 2010-2019",

\section{LANDASAN TEORI}




\section{Analisis Rasio Keuangan}

Pendapat Diana (2018:51) suatu kegiatan dengan membandingkan angka pada laporan keuangan guna memahami akan status financial perusahaan serta bisa mengukur kinerja manajemen diperiode tertentu disebut dengan analisisrasio keuangan.

\section{Jenis-Jenis Rasio}

1. Pendapat Diana (2018:58) rasio yang dapat menilai perkembangan perusahaan terhadap pembiayaan oleh pihak peminjam dana dibandingkan dengan modal disebut Debt To EquityRatio (DER).

Rumus DER yaitu :

$$
\mathrm{DER}=\frac{\text { Total utang (Liabilitas) }}{\text { Modal (Equity) }} \times 100 \%
$$

2. Pendapat Diana (2018:62) rasio yang dapat mengukur perkembangan perusahaan dalam mendapatkan laba melalui penjualan/pendapatan disebut dengan NPM (Net Profit Margin).

Rumus NPM yaitu :

$$
\mathrm{NPM}=\frac{\text { Laba Bersih setelah pajak }}{\text { Penjualan }} \times 100 \%
$$

3. Pendapat Diana (2018:63) rasio yang dapat menilai perkembangan perusahan dalam memperoleh keuntungan melalui seluruh asset yang perusahaan miliki disebut ROA (Return On Asset).

Rumus ROA yaitu :

\section{Harga Saham}

$$
\mathrm{ROA}=\frac{\text { Laba Bersih }}{\text { Total Aset }} \times 100 \%
$$

Pendapat Darmadji dan Fakhruddin (2012:10) terbentuknya harga akibat terjadinya penawaran dan permintaan atas saham dan terjadi pada pasar bursa yang ditetapkan oleh para pelaku pasar disebut dengan harga saham.

\section{Analisis Harga Saham}

Pendapat Budiman (2018:47) analisis harga saham memiliki tujuan dengan menentukan harga saham dari sebuah perusahaan karena telah terlalu mahal atau masih dapat menarik untuk di investasikan. Analisis harga saham yang digunakan adalah PER (Price Earing Ratio).

PER merupakan rasio yang dapat dihitung menggunakan cara membandingkan hargasaham yang beradar dipasar bursa denganlaba bersih per saham atau biasa disebut EPS.

Rumus PER yaitu :

$$
\text { PER }=\frac{\text { Harga Saham Per Lembar }}{\text { Earning Per Share }}
$$

\section{METODELOGI PENELITIAN}

\section{Desain Penelitian}

Pendapat Sanusi (2016:13) desain penelitian yaitu cetak biru untuk penelitian dan menggambarkan secara singkat tentang penelitian yang akan digunakan. Desain 
kuantitatif menjelaskan hubungan variabel dengan menganalisis data numeric dengan menggunakan cara statistik dan memiliki tujuan untuk menyatakan kebenaran, variabel, dan keadaan yang terjadi saat observasi berlangsung dan melalui pengujian hipotesis.

\section{Kerangka berfikir}

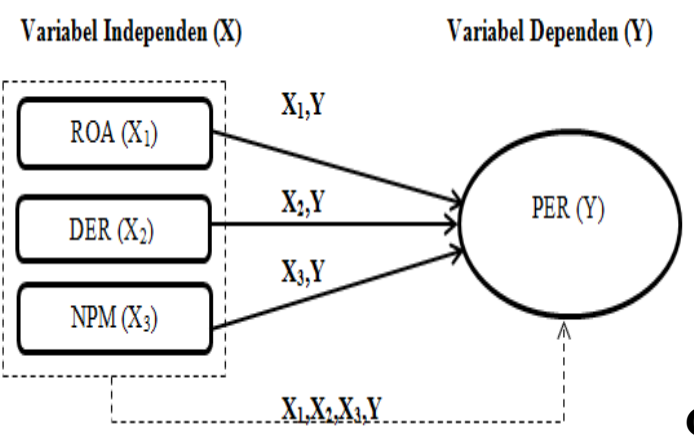

\section{Gambar 3.1}

Kerangka berfikir

sumber : sugiyono 2016

\section{Populasi dan Sampel}

\section{Populasi}

Pendapat Sugiyono (2016:80) area yang terdiri atas obyek/subyek serta memiliki ciri beserta ketentuan yang telah ditentukan agar dapat dipahami sehingga bisa menarik kesimpulan disebut dengan populasi. Populasi ang dugunakan pada penelitian ini yaitu seluruh perusahaan sub sektor tambang batubara yang terdaftar di BEI tahun 2010-2019.

\section{Sampel}

Pendapat Sugiyono (2016:81) jumlah yang dimiliki sebagian populasi disebut sampel. Sampel yang digunakan yaitu laporan keuangan tahunan perusahaan sub sektor tambang batubara yangterdaftar di BEI tahun 2010-2019. Dalam menentukan sampel padapenelitian ini dengan menggunakan teknik purposive sampling.

Nama-Nama Perusahaan Yang Terpilih
\begin{tabular}{|c|c|c|}
\hline No & Kode Saham & Nama Perusahaan \\
\hline 1 & ADRO & Adro Energy Tbk \\
\hline 2 & DOID & Delta Dunia Makmur Tbk \\
\hline 3 & PTBA & Tambang Batubara Bukit Asam Tbk \\
\hline
\end{tabular}

\section{Alat Analisis}

\section{Uji Asumsi Klasik}

Pendapat Lupiyoadi dan Ikhsan (2015:134) ada empat ujiasumsi klasik, adalah:

1. Uji Normalitas

Uji normalitas memilik tujuan yang berguna mengetahui apakah terdapat residual distribusi normal. Berikut merupakan cara yang dipakai guna melihat hasil uji normalitas melalui uji P-Plot dengan ketentuan apabila titik-titik yang menyebar dengan mengikuti garis diagonal sehingga memenuhi asumsi normalitas.

2. Uji Heteroskedastisitas 
Bentuk pegambilan keputusan jika adanya titik-titik meyebar dibawah dan diatas sumbu Y dan angka 0 sehingga tidak terjadi heteroskedastisitas

3. Uji Multikolonieritas

Guna mengetahui pada model regresi yang diperoleh mengalami gejala multikolonieritas diperhatikan melalui nilai VIF $<10$ sehingga tidak terdapat multikolonieritas.

4. Uji Autokorelasi

Guna melihat terdapat autokorelasi atau tidak dalam penelitian sehinggabisa dilakukan uji Durbin Watson melalui kriteriaapabiladl $<\mathrm{d}<(4-\mathrm{du})$, sehingga tidak ada autokorelasi

\section{Uji Regresi Liniear Berganda}

Menurut Purwanto (2017:226) bentuk persamaan dalam uji regresi liniear berganda terhadap penelitianini adalah:

Dimana :

$$
\mathbf{Y}=\mathbf{a}+\mathbf{b} 1 \mathbf{X}_{1}+\mathbf{b} 2 \mathbf{X}_{2}+\mathbf{b} 3 \mathbf{X}_{3}+\mathbf{e}
$$

$\mathrm{Y}=$ Variabel Dependen

$\mathrm{a}=$ Koefisien Konstanta

$\mathrm{b}=$ Koefisien Regresi Dari Masing-Masing Variabel

$\mathrm{X}=$ Variabel Independen

$\mathrm{e}=$ Koefisien error

\section{Koefisiensi Determinasi $\mathbf{R}^{2}$ (R Square)}

Pendapat Lupioyadi dan Ikhsan (2016:165) Penelitian ini menggunakan regresi liniear berganda dimana variabel $\mathrm{X}$ lebih dari dua sehingga untuk menentukan koefisien determinasi $\mathrm{R}^{2}$ yaitu dengan menggunakan Adjusted $\mathrm{R}^{2}$.

\section{Uji Hipotesis}

1. Uji Simultan (F)

Menurut Suharyadi dan Purwanto(2016:241) pengujian ini menjabarkan uji $\mathrm{F}$ yakni uji simultan atau hasil uji bersama-sama. Pada rancangan pengujian yang berkaitan dengan model regresi dapat diterima. Pada perhitungan hasil uji $\mathrm{F}$ ini akan dibandingkan dengan $\mathrm{F}_{\text {tabel }}$ yang didapat dengan menggunakan $\alpha(0,05)$.

2. Uji Parsial $(\mathrm{t})$

Menurut Suharyadi dan Purwanto (2016:244) pengujian ini memiliki tujuan guna menguji pengaruh variabel $\mathrm{X}$ terhadap variabel $\mathrm{Y}$ adalah melalui cara membandingkan $t_{\text {tabel }}$ dengan $t_{\text {hitung }}$ secara parsialyang didapatkan melalui $\alpha 0,05$.

\section{HASIL DAN PEMBAHASAN \\ Hasil Analisis Data \\ Asumsu Klasik}

1. Uji Normalitas

Hasil Uji P Plot 


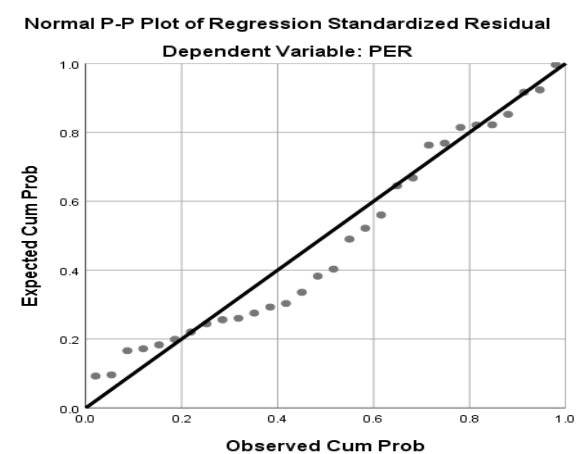

Gambar 4.1

Sumber : Output SPSS 25, diolah 2020

Pengujian menggunakan ujiP-Plot diketahui hasil dari uji P-Plot meperlihatkan titik-titik mengikut garis diagonal sehingga dengan demikian nilai residual telah berdistribusi normal

2. Uji Heteroskedastisitas

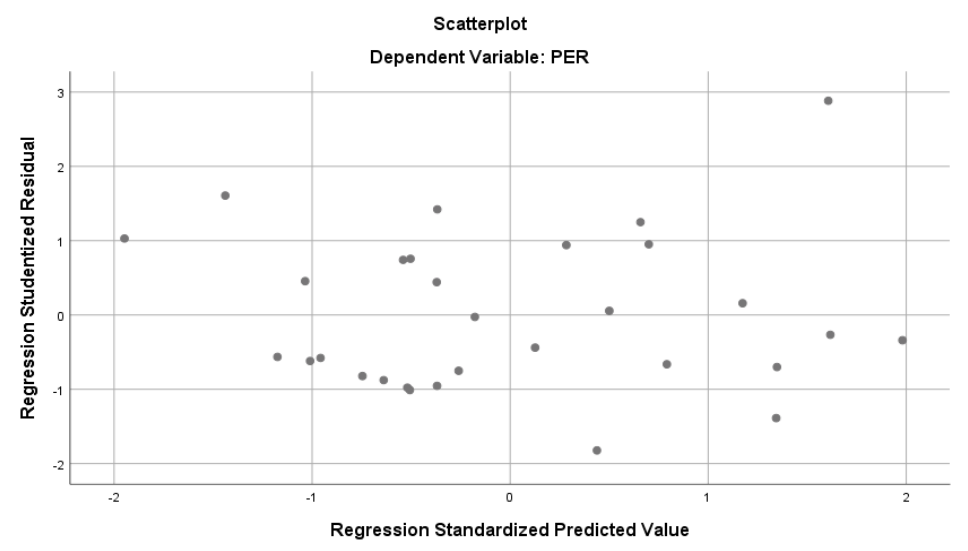

Gambar 4.2

Sumber : output SPSS 25, diolah 2020

Kesimpulandiatas dapat diketahui bahwa scatterplot menunjukan data dari penelitian yang telah dilakukan tidak mengandung heterosketastisitas.

3. Uji Multikolonieritas

Tabel 4.2

\begin{tabular}{|c|c|c|c|c|c|c|c|}
\hline \multirow[b]{2}{*}{ Model } & $\begin{array}{l}\text { Unstand } \\
\text { Coeffi }\end{array}$ & $\begin{array}{l}\text { rdized } \\
\text { ents }\end{array}$ & $\begin{array}{l}\text { sil Uji Multi } \\
\text { efficients }^{\text {a }} \\
\text { Standardi } \\
\text { zed } \\
\text { Coefficien } \\
\text { ts }\end{array}$ & olonier & & $\begin{array}{r}\text { Collir } \\
\text { Stat }\end{array}$ & $\begin{array}{l}\text { arity } \\
\text { ics }\end{array}$ \\
\hline & B & $\begin{array}{l}\text { Std. } \\
\text { Error }\end{array}$ & Beta & $t$ & Sig. & $\begin{array}{c}\text { Tolera } \\
\text { nce }\end{array}$ & VIF \\
\hline $\begin{array}{ll}1 & \text { (Consta } \\
\text { nt) }\end{array}$ & 6.816 & 2.361 & & 2.887 & .008 & & \\
\hline
\end{tabular}




\begin{tabular}{l|l|l|l|l|l|l|l|}
\hline ROA & .824 & .288 & 1.088 & 2.855 & .008 & .172 & 5.807 \\
\hline DER & -.171 & .268 & -.114 & -.638 & .529 & .780 & 1.282 \\
\hline NPM & -.494 & .299 & -.659 & -1.652 & .110 & .157 & 6.358 \\
\hline
\end{tabular}

a. Dependent Variable: PER

Sumber: Output SPSS 25, diolah 2020

Hasil pada penelitian menunjukan bahwa variabel independenmempunyai nilai VIF $<10$ dengan nilai Tolerance $>0,10$. Makatidak ada gejala multikolonieritas.

4. Uji Autokorelasi

Tabel 4.3

Hasil Uji Autokorelasi

Model Summary

\begin{tabular}{lr|r|r|r|r} 
Model & $\mathrm{R}$ & $\mathrm{R}$ Square & $\begin{array}{c}\text { Adjusted R } \\
\text { Square }\end{array}$ & $\begin{array}{c}\text { Std. Error of } \\
\text { the Estimate }\end{array}$ & $\begin{array}{c}\text { Durbin- } \\
\text { Watson }\end{array}$ \\
\hline 1 & $.592^{\mathrm{a}}$ & .350 & .275 & 4.95413 & 2.340 \\
\hline
\end{tabular}

a. Predictors: (Constant), NPM, DER, ROA

b. Dependent Variable: PER

Sumber : Output SPSS 25, diolah 2020

$$
\begin{aligned}
& \mathrm{du}=1,649 \\
& \mathrm{~d} l=1,213
\end{aligned}
$$

Pada tabel 4.3 menunjukan nilai Durbin-Watson 2,340 dimana nilai Durbin-Waston terletak antara batas Upper Durbin (du) dengan nilai 1,649 dan Lower Durbin (dl) dengan nilai 1,213 maka, dapat disimpulkan menjadi $1,213<2,340<(4-1,649=2,351)$. Sehingga tidak terjadigangguan autokorelasi.

\section{Uji Regresi Linier Berganda}

Tabel 4.4

Hasil Uji Regresi Linier Berganda Coefficients $^{\mathrm{a}}$

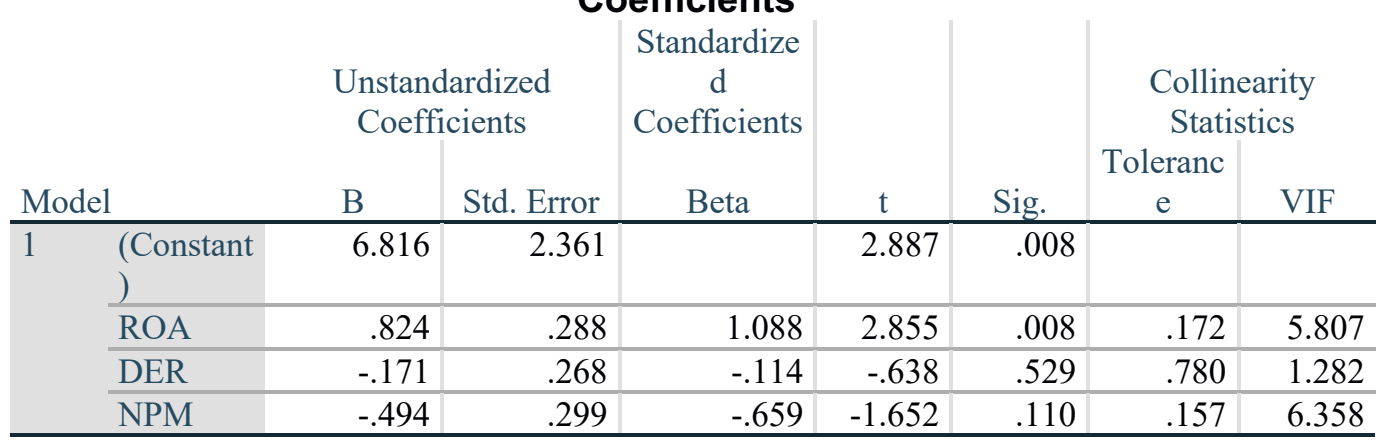

a. Dependent Variable: PER

Sumber : Output SPSS 25, diolah 2020

Persamaan regresi linier berganda pada tabel 4.4 adalah :

$$
\operatorname{PER}(\mathrm{Y})=6,816+0,824 \mathrm{X}_{1}-0,171 \mathrm{X}_{2}-0,49 \mathrm{X}_{3}+\mathrm{e}
$$

Pada bentuk persamaan diatas sehingga dapat dianalisis yaitu :

1. Nilai koefisien konstanta dalam 
persamaan regresi linier berganda adalah sebesar 6,816. Hal ini menunjukan apabila variabel bebas $\operatorname{ROA}\left(\mathrm{X}_{1}\right), \operatorname{DER}\left(\mathrm{X}_{2}\right), \operatorname{NPM}\left(\mathrm{X}_{3}\right)$ dianggap konstan sehingga nilai PER sebesar 6,816.
2.
$\operatorname{ROA}\left(\mathrm{X}_{1}\right)$

ROA merupakan nilai koefisien regresi variabel ROA $\left(\mathrm{X}_{1}\right)$ terhadap variabel PER $(\mathrm{Y})$, artinya apabila ROA $\left(\mathrm{X}_{1}\right)$ mengalami penambahan satu satuan sehingga tingkat PER akan terjadikenaikan sebesar 0,824, dengan asumsi variabelbebas lainnya konstan. Hal ini menunjukan terdapat pengaruh positif antara $\mathrm{ROA}\left(\mathrm{X}_{1}\right)$ dengan PER.
3.
$\operatorname{DER}\left(\mathrm{X}_{2}\right)$

DER merupakan nilai koefisien regresi variabel DER $\left(\mathrm{X}_{2}\right)$ terhadap PER $(\mathrm{Y})$, artinya apabila DER $\left(\mathrm{X}_{2}\right)$ terdapat penambahan satu satuan sehingga tingat PER akan terjadi penurunan sebesar 0,171 , dengan asumsivariabel bebas lainnya konstan. Hal ini menunjukan terdapat pengaruh negatif antara DER $\left(\mathrm{X}_{2}\right)$ dengan PER.

4.

$\operatorname{NPM}\left(\mathrm{X}_{3}\right)$

NPM merupakan nilai koefisien regresi variabel NPM $\left(\mathrm{X}_{3}\right)$ terhadap PER $(\mathrm{Y})$, artinya apabila NPM $\left(X_{3}\right)$ mengalami penambahan satu satuan sehingga PER akan terjadi penurunan sebesar 0,494, dengan asumsi variabel bebaslainnya konstan. Hal ini menunjukan terdapat pengaruh negatif antara NPM $\left(\mathrm{X}_{3}\right)$ dengan PER.

\section{Uji Koefisiensi Determasi $\mathbf{R}^{2}$ (R Square)}

Tabel 4.5

\section{Hasil Uji Koefisiensi Determinasi $\mathbf{R}^{2}$ (R Square)} Model Summary

\begin{tabular}{lr|r|r|r|r} 
Model & $\mathrm{R}$ & R Square & $\begin{array}{c}\text { Adjusted R } \\
\text { Square }\end{array}$ & $\begin{array}{c}\text { Std. Error of } \\
\text { the Estimate }\end{array}$ & $\begin{array}{c}\text { Durbin- } \\
\text { Watson }\end{array}$ \\
\hline 1 & $.592^{\mathrm{a}}$ & .350 & .275 & 4.95413 & 2.340 \\
\hline
\end{tabular}

a. Predictors: (Constant), NPM, DER, ROA

b. Dependent Variable: PER

Sumber : Output SPSS 25, diolah 2020

Tabel 4.4 menunjukan besarnya nilai Adjusted $\mathrm{R}^{2}$ yaitu $0,275,27,5 \%$. Angka tersebut mengandung variabel $\mathrm{ROA}\left(\mathrm{X}_{1}\right), \operatorname{DER}\left(\mathrm{X}_{2}\right)$, dan $\mathrm{NPM}\left(\mathrm{X}_{3}\right)$ berpengaruh terhadap PER (Y).

1. Uji parsial (t)

\begin{tabular}{|c|c|c|c|c|c|c|c|}
\hline \multirow[b]{2}{*}{ Model } & \multicolumn{2}{|c|}{$\begin{array}{l}\text { Unstandardized } \\
\text { Coefficients }\end{array}$} & \multirow{2}{*}{$\begin{array}{c}\text { Standardi } \\
\text { zed } \\
\text { Coefficien } \\
\text { ts } \\
\text { Beta }\end{array}$} & \multirow[b]{2}{*}{$\mathrm{t}$} & \multirow[b]{2}{*}{ Sig. } & \multicolumn{2}{|c|}{$\begin{array}{c}\text { Collinearity } \\
\text { Statistics }\end{array}$} \\
\hline & $B$ & $\begin{array}{l}\text { Std. } \\
\text { Error }\end{array}$ & & & & $\begin{array}{c}\text { Tolera } \\
\text { nce }\end{array}$ & VIF \\
\hline $\begin{array}{ll}1 & \text { (Consta } \\
\text { nt) }\end{array}$ & 6.816 & 2.361 & & 2.887 & .008 & & \\
\hline ROA & .824 & .288 & 1.088 & 2.855 & .008 & .172 & 5.807 \\
\hline DER & -.171 & .268 & -.114 & -.638 & .529 & .780 & 1.282 \\
\hline NPM & -.494 & .299 & -.659 & -1.652 & .110 & .157 & 6.358 \\
\hline
\end{tabular}

a. Dependent Variable: PER

Sumber : Output SPSS 25, diolah 2020 
Berikut disajikan hasil uji t pada variabel $\mathrm{X}$ adalah sebagai berikut :

$$
\begin{aligned}
\mathrm{T}_{\text {tabel }} & =(\mathrm{df}=\mathrm{n}-\mathrm{k}) \\
& =30-4 \\
& =26
\end{aligned}
$$

Berdasarkan tabel 4.6berikut adalah penjelasan pada masing-masing variabel :

a. Variabel bebas ROA $\left(\mathrm{X}_{1}\right)$ didapat nilai thitung 2,855serta $\operatorname{sig} 0,008<0,05$. Karena $t_{\text {hitung }}>t_{\text {tabel }}(2,855>2,055)$, sehingga variabel ROA $\left(\mathrm{X}_{1}\right)$ secara parsial berpengaruh dan sig terhadap PER pada perusahaan sun sektor tambang batubara yang terdaftar di BEI tahun 2010-2019.

b. Variabel bebas DER (X2) didapat nilai thitung0,638 serta sig0,529 $>0,05$. Kerena $t_{\text {hitung }}<t_{\text {tabel }}(0,638<2,055)$, sehingga variabel DER secara parsial tidak berpengaruh serta tidak sig terhadap PER pada perushaan sub sektor tambang batubara di BEItahun 2010-2019.

c. Variabel independen NPM (X3) didapat nilai thitung1,325 serta sig 0,110> 0,05 . Karena $t_{\text {hitung }}<t_{\text {tabel }}(1,325<2,055)$, sehinggavariabel NPM secara parsial tidak perpengaruh serta tidak sig terhadap PER pada perushaan sub sektor tambang batubara di BEI tahun 2010-2019.

\section{KESIMPULAN DAN SARAN}

\section{Kesimpulan}

Kesimpulan pada hasil pengujian menunjukan bahwa :

1. ROA, DER, dan NPM berpengaruh secara simultan terhadap PER pada perusahaan sub sektor tambang batubara yang terdaftar di BEI tahun 2010-2019.

2. ROA berpengaruh secara parsial terhadap PER pada perusahaan sub sektor tambang batubara yang terdaftar di BEI tahun 2010-2019.

3. DER tidak berpengaruh secara parsial terhadap PER pada perusahaan sub sektor tambang batubara yang terdaftar di BEI tahun 2010-2019.

4. NPM tidak berpengaruh secara parsial terhadap PER pada perusahaan sub sektor tambang batubara yang terdaftar di BEI tahun 2010-2019.

\section{Saran}

1. Pada perusahaan sub sektor tambang batubara sebaiknya agar menjaga kestabilan kinerja keuangan pada ROA perusahaan dan dapat memaksimalkan kinerja keuangan terutama DER dan NPM agar perusahaan dapat dinilai sehat terutama bagi para calon investor yang akan memberikan investasinya kepada emiten.

2. Perusahaan sub sektor tambang batubara dapat menyakinkan para investor dengan lebih meningkatkan nilai kinerja ROA agar tetap stabil pergerakannya yang mungkin akan mempengaruhi PER perusahaan.

3. Perusahaan sub sektor tambang batubara dapat menjaga nilai DER dan NPM dengan memperbaiki kinerja perusahaan yang mungkin dapat mempengaruhi PER dan mempengaruhi minat para investor untuk berinvestasi supaya dapat menunjang keberhasilan perusahaan sehingga akan tetap bersaing dengan perusahaan lainnya.

\section{REFERENSI}


Budiman, Raymond. .2019 Rahasia Analisis Fundanmental Saham. Jakarta. Penerbit : PT. elex Media Komputindo.

Diana, Shinta Rahma. 2018. Analisis Laporan Keuangan. Bogor. Penerbit : In Media.

Fakhruddin, Hendy M dan Darmadji Tjiptono. 2012. Pasar Modal Di Indonesia. Jakarta. Penerbit : Salemba Empat.

Fakultas. Bisnis. 2020. Buku Panduan Penulisan Skripsi \& Tugas Akhir Universitas Mitra Indonesia 2019-2020.

Lupiyoadi, Rambat dan Ridho Bramulya Ikhsan. 2015. Praktikum Metode Riset Bisnis. Jakarta : Penerbit Salemba Empat,

Manoppo, Ch. O. Vera, Bermhard Tewal, Arrazi Bin Hasan Jan. Pengaru Current Ratio, Der, Roa, Dan Npm Terhadap Harga Saham Pada Perusahaan Food And Beverages Yang Terdaftar Di BEI (Periode 2013-2015). Universitas Sam Ratulangi Manado. 2017.

Sanusi, Anwar. 2016. Metodologi Penelitian Bisnis. Jakarta. Penerbit : Salemba Empat..

Sugiyono. 2016. Metode Penelitian Kuantitatif, kualitatif, dan R\&D. Bandung. Penerbit : Alfabeta.

Suharyadi dan Purwanto. S.K. 2016. Statistika Untuk Ekonomi Dan Keuangan Modern. Jakarta : Penerbit Salemba Empat

https://www.idx.co.id (diakses 12/02/2020)

https://www.sahamok.com (diakses 20/02/2020)

https://id.wikipedia.org/wiki/Bursa efek (diakses 25/03/2020)

https://www.Indonesia-invesments.com (diakses 21/03/2020)

https://www.cnbcindonesia.com (diakses 25/03/2020)

https://www.bps.go.id (diakses 28/03/2020) 